\title{
Characterisation of corrosion products on copper-based artefacts: potential of MA-XRF measurements
}

\author{
Elisabetta Di Francia ${ }^{1}$, Sabrina Grassini ${ }^{1}$, Giovanni E. Gigante ${ }^{2}$, Stefano Ridolfi ${ }^{3}$, Sergio A. Barcellos \\ Lins $^{2,4}$
}

1 Politecnico di Torino, Corso Duca degli Abruzzi 24 - 10129, Turin, Italy

${ }^{2}$ La Sapienza Università di Roma, Via Antonio Scarpa 14/16 - 00161, Rome, Italy

${ }^{3}$ Ars Mensurae, Via Vincenzo Comparini $101-00188$, Rome, Italy

${ }^{4}$ Surface Analysis Laboratory INFN Roma Tre, Via della Vasca Navale 84 -00146, Rome, Italy

\begin{abstract}
The use of macro-X-ray fluorescence (MA-XRF) scanners is now widespread in cultural heritage applications. However, its use for the characterisation of metallic works of art is still limited. In this study, a novel portable MA-XRF scanner prototype was tested on artificially corroded copper samples to assess its analytical capabilities on corroded metals, yielding information on the spatial distribution of the corrosion products grown on the metal's surface. A multi-analytical approach was used to thoroughly characterise the copper samples and compare the obtained results to verify the reliability of the MA-XRF data. The prototype was able to obtain distribution maps of different elements, such as sulphur and chlorine, which can be directly correlated to different corrosion products. With the use of imaging filtering techniques, it was possible to investigate the stratification of the corrosion product layers and observe gradients in the distribution of certain elements.
\end{abstract}

\section{Section: RESEARCH PAPER}

Keywords: Cu-based alloys; artificial corrosion products; FESEM; $\mu$ XRD; MA-XRF

Citation: Elisabetta Di Francia; Sabrina Grassini; Giovanni Ettore Gigante; Stefano Ridolfi; Sergio Augusto Barcellos Lins, Characterisation of corrosion products on copper-based artefacts: potential of MA-XRF measurements, Acta IMEKO, vol. 10, no. 1, article 18, March 2021, identifier: IMEKO-ACTA10 (2021)-01-18

Editor: Carlo Carobbi, University of Florence, Italy

Received May 11, 2020; In final form September 8, 2020; Published March 2021

Copyright: This is an open-access article distributed under the terms of the Creative Commons Attribution 3.0 License, which permits unrestricted use, distribution, and reproduction in any medium, provided the original author and source are credited.

Funding: This project has received funding from the European Union’s Horizon 2020 research and innovation programme under the Marie Skłodowska-Curie grant agreement No. 766311

Corresponding author: Sergio A. Barcellos Lins, e-mail: sergio.lins@roma3.infn.it

\section{INTRODUCTION}

The study of corrosion products, their morphology and chemical, physical and microstructural characterisation, is of considerable interest to heritage and conservation sciences. Metallic objects are unique artefacts that can be considered a witness to the past and a record of a society's technological prowess. Therefore, it is of the utmost importance to study and preserve such objects.

To achieve this goal, a transdisciplinary approach is always preferable; measurement, instrumentation and material sciences find a point of commonality in conservation science. In fact, metrological and material characterisation are combined in measuring and quantifying the conservation state of artefacts and the aggressiveness of the surrounding environment with a common final goal, the preservation, restoration and safeguarding of objects [1]-[6]. Numerous studies on ancient and historical copper $(\mathrm{Cu})$-based artefacts have tried to establish the chemical characteristics and structure of the natural patinas that grow on objects that have been buried in soil for long periods. The long-time corrosion of $\mathrm{Cu}$-based alloys leads to structural alloy transformations and to the growth of surface corrosion product layers with complex and stratified structures, the investigation of which allows important information on degradation mechanisms to be obtained [7], [8]

Corrosion in soil leads to the formation of different patinas and corrosion product layers, whose chemical composition and microstructure depend not only on the alloy composition but also on the environmental conditions and soil chemico-physical properties (for example, $\mathrm{pH}$, organic and inorganic particles, aggressive ions and oxygen content). Usually, an inner layer of cuprite $\left(\mathrm{CuO}_{2}\right)$ forms on the metal surface, and then, an outer layer, composed of different copper oxides and 
hydroxychlorides, sulphates and carbonates, such as malachite, brochantite, atacamite and paratacamite, develops [9]-[12]. Since the external layers are generally quite porous, a continuous interaction between the metallic surface and the environment occurs. In particular, when reactive copper chloride $(\mathrm{CuCl}$, nantokite) is formed during burial, it can react with oxygen and humidity, leading to a cyclic copper corrosion process, known as bronze disease [13]-[15], in which chloride ions undergo a catalytic action towards further degradation.

To study the corrosion phenomenon and extract as much information as possible, multi-analytical strategies are often employed. Within the analytical techniques available, those that are non-destructive are commonly preferred when dealing with historical and archaeological artefacts, and of these, X-ray fluorescence (XRF) is a staple for evaluating chemical composition [16]-[18]. As a matter of fact, the most important preliminary action in the study of the conservation state of $\mathrm{Cu}$ based artefacts is to assess the presence of aggressive agents, such as chloride ions, and unstable corrosion products that can be dangerous for the preservation of the object, which, therefore, needs immediate stabilisation.

In this context, the development of methodologies and portable instruments for quantitative analyses and elemental map distribution, which could also be employed in the field, can be important tools in conservation. Moreover, copper and other alloy components and soil element distribution maps could help in obtaining information on degradation mechanisms and be very useful for developing tailored and suitable cleaning and stabilisation treatments before artefact restoration.

In the past few years, macro-X-ray fluorescence (MA-XRF) has been extensively used to study paintings, frescoes and stained glass [19]-[21], having the obvious advantage over traditional $\mathrm{XRF}$ analysis of yielding an immediate and visual interpretation of the spatial distribution of chemical elements. This advantage can be fully explored in the study of inhomogeneous samples, such as corroded bronzes and other metallic archaeological artefacts. Therefore, MA-XRF can be considered an efficient and powerful measuring tool for detecting the presence of active corrosion products, which are particularly dangerous for the long-lasting preservation of the artefact. Using MA-XRF scanning, it is possible to provide a better, macro understanding of the corrosion product multi-layer structure by simply detecting the depth elemental distribution from the surface towards the bulk metal.

In this study, a portable MA-XRF scanner prototype, built by the Sapienza University of Rome, Istituto Nazionale di Fisica Nucleare (INFN) - Roma TRE division, and Ars Mensurae, was used to characterise a set of artificially corroded copper reference specimens simulating real archaeological corrosion products grown on Cu-based alloys. Due to the stratification and heterogeneity of real corrosion product layers formed on $\mathrm{Cu}$ based artefacts, reference samples were chosen for the optimisation of the proposed analytical methodology and for the preliminary assessment of the developed prototype performance in order to verify whether the obtained results were meaningful [22].

The second section of this article describes the reference sample and the analytical techniques used to characterise them, with particular attention to the description of the main features of the MA-XRF scanner prototype. In the following section, the results obtained on the reference samples are illustrated and discussed. Finally, the concluding section summarises the key findings.

\section{MATERIALS AND METHODS}

\subsection{Reference samples}

Copper reference samples (Cu 99.96 wt.\%; $45 \times 15 \times 5 \mathrm{~mm}^{3}$ ) were polished with 500 to 4000 grit $\mathrm{SiC}$ paper, rinsed in ethanol in an ultrasonic bath for 5 minutes and dried well. Two types of artificial corrosion layer were then produced by chemical synthesis.

A set of $\mathrm{Cu}$ reference samples were immersed in an aggressive solution, according to the ASTM D1384 standard method $\left(2.8 \cdot 10^{-2} \mathrm{M} \mathrm{NaCl}, 0.01 \mathrm{M} \mathrm{Na} \mathrm{SO}_{4}, 16.1 \cdot 10^{-2} \mathrm{M} \mathrm{NaHCO}_{3}\right.$; modified by Constantinides [23]), for three months at room temperature (sample $A$ ). The other sample set was artificially aged by immersion in a sulphate-containing solution $\left(0.1 \mathrm{M} \mathrm{Na}_{2} \mathrm{SO}_{4}\right)$ for three months at room temperature (sample B). None of the solutions were stirred or aerated by bubbling.

\subsection{MA-XRF scanning}

The MA-XRF prototype instrument developed in this study is composed of an $\mathrm{x}-\mathrm{y}$ motorised stage with a sample holder and a detachable scanning head. A scheme of the experimental setup is shown in Figure 1.

The head comprises a collimated, low-power Ta-target Moxtek ${ }^{\circledR}$ X-ray tube and a lightweight X-123SDD detector from AMPTEK ${ }^{\circledR}$ with a $125-\mathrm{eV}$ resolution at the $\mathrm{Mn} \mathrm{K} \alpha$ emission line. The scanning head remains fixed while the sample is translated in the stage with a maximum step resolution of $100 \mu \mathrm{m}$. The system is controlled by a custom-made interface programmed in $\mathrm{LabView}^{\mathrm{TM}}$ with a near-live display of the counts (intensity) map.

An earlier version of the prototype system, using a larger translation stage, has been used previously to study archaeological painted and gilt leathers [24], while an improved, more recent iteration of the portable version was recently used to study a gilded $\mathrm{Cu}$-based artefact [25]. The portable instrument is described in more detail elsewhere [26].

The data was collected with a step resolution of $1 \mathrm{~mm}$, dwelltime of 5 seconds and a total mapped area of $43 \times 13 \mathrm{~mm}^{2}$ per sample, which was enough to cover the surface. Tube voltage was set at $35 \mathrm{KV}$, the current at $17 \mu \mathrm{A}$ and each scan took about 54 minutes.

Elemental distribution maps were generated with an earlier version of the open-source data analysis software XISMuS [27], embedded with low and high thresholding and $3 \times 3$ iterative smoothening imaging filters.

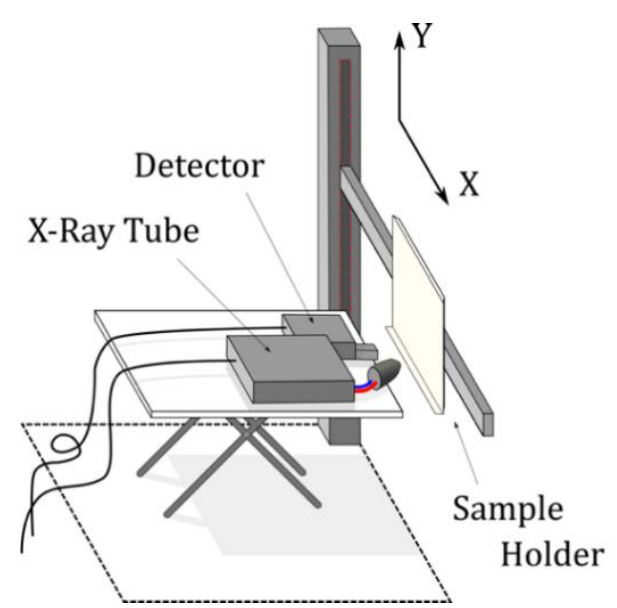

Figure 1. MA-XRF prototype: the X-ray tube, the detector and the sample holder with the $x-y$ motorised stage. 

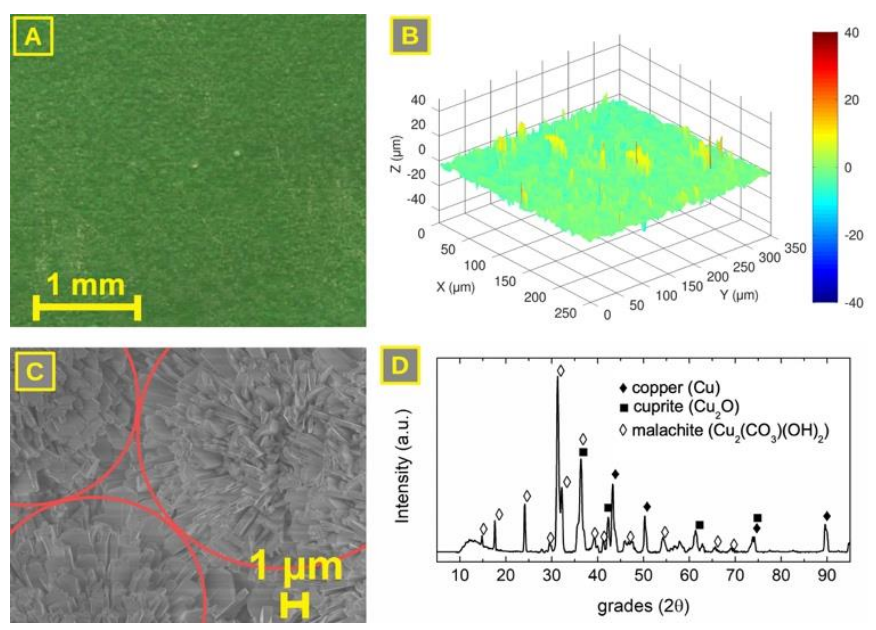

Figure 2. Sample A: (A) high-resolution surface picture; (B) confocal microscope image; (C) FE-SEM image showing the crystals grouped in circular shapes; (D) $\mu$ XRD pattern identification.

\subsection{Reference sample characterisation}

The artificially corroded $\mathrm{Cu}$ reference samples were first characterised by means of different analytical techniques, such as high-resolution digital photography, confocal microscopy, micro-X-ray diffraction ( $\mu$ XRD) and field emission scanning electron microscopy (FE-SEM), coupled with energy dispersive spectroscopy (EDS) to collect information on the chemical composition of the corrosion products and on surface roughness and morphology. All these data are necessary for the optimisation of the MA-XRF measurement setup and to identify the main experimental parameters that could affect the obtained results.

High resolution digital photographs were acquired using a digital camera $\left(4000 \times 3000\right.$ pixel $^{2}$, Panasonic Lumix G2) equipped with a stand with a $3000 \mathrm{~K}$ lamp.

Roughness evaluations were performed on the acquired profiles by means of a Sensofar PL $\mu 2300$ confocal microscope (CM) using a 20x objective. The images were processed in the free Octave software and surface standard deviation was computed on about 100,000 points, which compose the confocal pictures.

MXRD spectra were collected by a D-MAX Rapid Rigaku instrument equipped with RINT/RAPID software. This instrument presents a 2D-curved imaging plate detector (IP, a flexible sheet coated with white -or light-blue-photoluminescent material consisting of $\mathrm{BaFBr}: \mathrm{Eu}^{2+}$ ), and a very brilliant rotating anode $\left(\mathrm{Cu} \mathrm{K}_{\alpha}\right)$ with a spot size of $\approx 70 \mu \mathrm{m}$. Diffractions were acquired with the X-ray source at $40 \mathrm{kV}$ and $20 \mathrm{~mA}$ with a $100 \mu \mathrm{m}$ collimator in the range of $10^{\circ}$ to $160^{\circ} 2 \theta$. The elaboration and qualitative identification of the diffraction patterns were achieved using X'Pert HighScore Plus v3.0e software and comparison with the PDF and ICSD database.

FE-SEM (Zeiss, Supra40) images were collected in in-field emission mode by varying the acceleration voltage in the range of $1.5 \mathrm{kV}$ to $15 \mathrm{kV}$. EDS analyses were performed using the EDS INCA x-sight (Oxford instruments) with an acceleration voltage of $15 \mathrm{kV}$ at a working distance of $8.5 \mathrm{~mm}$.

Finally, the $\mathrm{Cu}$ reference samples were characterised by means of the MA-XRF analysis using the scanner prototype, as discussed above, to collect information on the chemical element distribution to identify the presence of different corrosion products on the sample's surface.
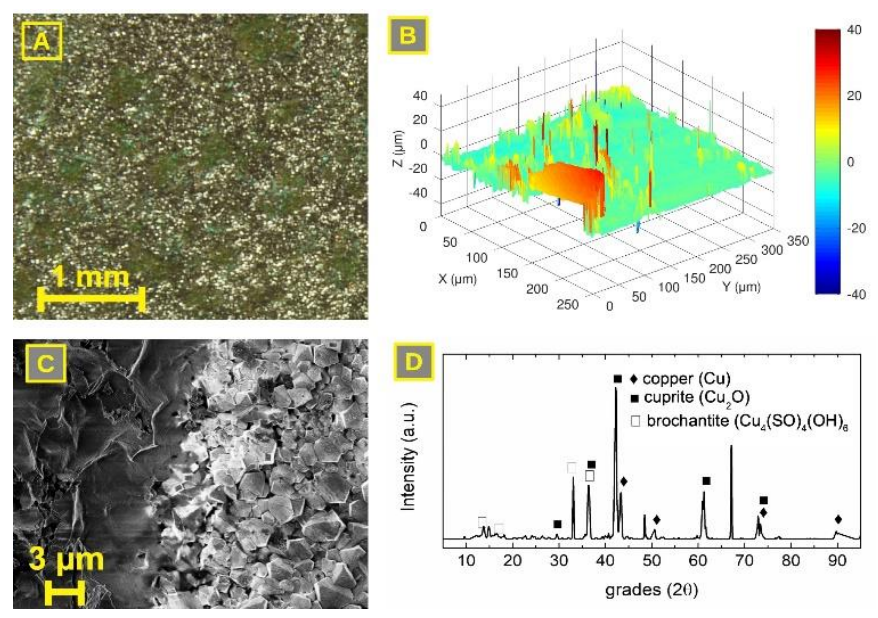

Figure 3. Sample B: (A) high-resolution surface picture; (B) confocal microscope image; (C) FE-SEM image showing the corrosion product morphology; (D) $\mu \mathrm{XRD}$ pattern identification.

\section{RESULTS AND DISCUSSION}

The accelerated corrosion procedures applied to the copper reference samples led to the growth of different artificial corrosion product layers.

\subsection{Reference sample $A$}

Looking at the surface and the high-resolution image, the corrosion product layer formed by exposing the $\mathrm{Cu}$ reference samples to the ASTM D1384 solution (sample A) appears uniformly green in colour, with a corrosion product layer that is quite homogenous and well adhered to the metal surface (Figure 2A).

The CM image acquired showed a relatively smooth surface. The CM mainly allows the estimation of the standard deviation of the height, which is about $2.7 \mu \mathrm{m}$ (Figure 2B); therefore, a rather uniform surface is observed.

At microscopic level, the FE-SEM image (Figure 2C) shows a surface well covered by tabular crystals of $1 \mu \mathrm{m}$ in length and grouped in circular shapes. EDS analyses, performed on the crystals, identified the presence of $\mathrm{O}, \mathrm{C}$ and $\mathrm{Cu}$, with a typical composition of $\approx 54$ wt. $\%$ of $\mathrm{Cu}, \approx 34 \mathrm{wt} . \%$ of $\mathrm{O}$ and $\approx 12 \mathrm{wt} . \%$ of C.

The $\mu$ XRD patterns (Figure 2D) mainly reveal the presence of metallic copper (Cu, ICSD code: 53757$)$, cuprite $\left(\mathrm{Cu}_{2} \mathrm{O}, \mathrm{ICSD}\right.$ code: 52043) and malachite $\left(\mathrm{Cu}_{2}\left(\mathrm{CO}_{3}\right)(\mathrm{OH})_{2}\right.$, ICSD code: 15384). The presence of malachite seems confirmed also by the EDS analyses; the weight percentage of $\mathrm{Cu}-\mathrm{O}-\mathrm{C}$ are close to those detected on malachite reported in the literature [28]. Based on the EDS and $\mu \mathrm{XRD}$ analyses, it is reasonable to assume that the corrosion product layer is structured in an external layer composed mainly of malachite and an inner layer of cuprite. The metallic copper comes from the bulk, which is evidence of the low thickness of the corrosion product layer.

In summary, the morphological and microstructural analyses highlighted that sample $A$ presents a homogenous corrosion product layer characterised by the presence of relatively small crystals, visible on the surface and composed mainly of malachite. The presence of an inner layer of cuprous oxide is also detected.

The chemical and microstructural characterisation of the corrosion products do not provide evidence of the presence of copper chlorides, probably due to the hydrolysis of nantokite 
$(\mathrm{CuCl})$ in the solution, which leads to the formation of cuprite on the metal surface.

\subsection{Reference sample B}

Observing the high-resolution image, the surface of sample $B$ appears quite variable in colour, with green-to-brown corrosion products mixed together on the copper surface (Figure 3A). The corrosion product layer formed in the sulphate-containing solution appears well adhered to the metal.

Compared to sample $A$, the surface of sample $B$ presents a more heterogeneous morphology, with a standard deviation of the flat part of about $6.1 \mu \mathrm{m}$ (Figure 3B). A high surface roughness is therefore evidenced.

Microscopically, FE-SEM observation confirmed the presence of a heterogeneous corrosion product layer, showing the presence of two different types of area (Figure 3C). One area was characterised by the absence of identifiable crystals and a composition of $\approx 56 \mathrm{wt} . \%$ of $\mathrm{Cu}, \approx 36 \mathrm{wt} . \%$ of $\mathrm{O}$ and $\approx 8 \mathrm{wt}$. $\%$ of $\mathrm{S}$ (Figure 3C, dark area), whereas the other area was composed of well-defined and identifiable cubic crystals of less than $2 \mu \mathrm{m}$ in size (Figure 3C, bright area). The crystals presented a typical composition of $\approx 89$ wt. $\%$ of $\mathrm{Cu}$ and $\approx 11$ wt. $\%$ of $\mathrm{O}$, which relates to the cuprite composition [29].

The $\mu$ XRD diffractograms, performed on several points of the surfaces (Figure 2D), consistently highlighted the presence of metallic copper (Cu, ICSD code: 53246) (possibly coming from the bulk) and cuprite $\left(\mathrm{Cu}_{2} \mathrm{O}\right.$, ICSD code: 173982). The occurrence of brochantite $\left(\mathrm{Cu}_{4}\left(\mathrm{SO}_{4}\right)(\mathrm{OH})_{6}\right.$, ICSD code: 97703$)$ and posnjakite $\left(\mathrm{Cu}_{4}\left(\mathrm{SO}_{4}\right)(\mathrm{OH})_{6}\left(\mathrm{H}_{2} \mathrm{O}\right)\right.$, ICSD code: 100276 - not shown in the figure) were also detected.

The chemical, morphological and microstructural analyses highlighted that sample $B$ presents a heterogeneous corrosion product layer, characterised by the presence of areas of small cuprite crystals and of other areas where other compounds, mainly copper sulphates, are spread around cuprite crystals.

\subsection{Scanner characterisation and performance}

The artificially corroded reference samples were analysed by MA-XRF scanning, and illustrative pictures of the analysed areas were taken with a DSLR camera with no white balance correction and no external light source.

\subsubsection{Reference sample $A$}

Figure 4 shows the total counts (sum) map alongside the elemental maps and a picture of the surface of sample $A$ after being immersed for a long-time in a carbonate and chloridecontaining solution.

The sum map is created by summing every count in the pixel spectrum and attributing that value to a pixel, in a 'flattening' fashion, transforming the $\mathrm{n}$-dimension pixel (where $\mathrm{n}$ represents the number of spectrum channels) to a 1-dimension pixel. Therefore, the higher the pixel value, the more counts collected.

Figure 4 indicates the presence of chlorine in sample $A$. However, when verifying the unprocessed chlorine map, the signal appeared unusually concentrated in the bottom right of the image. The image was processed and filtered to enhance the darker parts and verify if any signal was being supressed by the higher intensity signal. This may happen given the 0-255 dynamic range of the grayscale maps. The processed image is shown in Figure 4E, where a very low-signal map can be observed, obtained by applying a low-pass and smoothening filter. This process cuts off the higher intensity values (brighter pixels) and smooths the image by taking the nearest-neighbours average, weighted at the centre. Only then could a portion of the

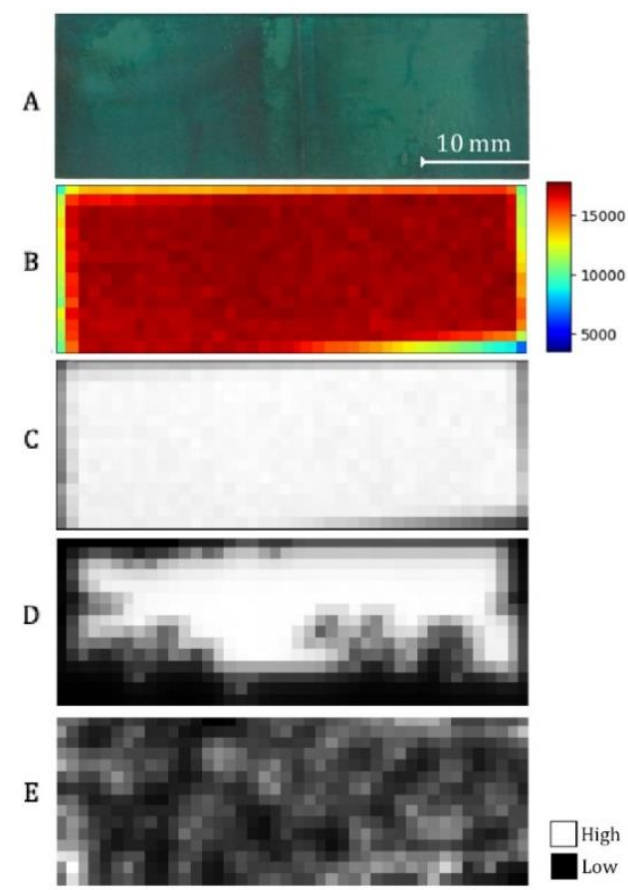

Figure 4. Sample A surface (A) and scans: (B) sum map; (C) copper map; (D) filtered copper map; (E) highly enhanced noise map obtained at chlorine $\mathrm{K}-\alpha$ energy range.

higher intensity signal be cleared. Even though a highly manipulated image could be generated, in this case it only represented noise and could not be considered an indication of chlorine. It is very likely that the detected signal came from the sample holder (made from polyvinyl chloride) and not from the sample itself. This has been confirmed by the diffractogram collected on sample A (Figure 2D), which demonstrates that the corrosion compounds present on the sample's surface are mainly composed of copper oxide and malachite. Moreover, the copper distribution map did not show any gradients (Figure 5), confirming the presence of a homogeneous corrosion product layer.

If chloride compounds were present, their detection would be almost impossible. Constantinides et al. [23] demonstrated, through artificially corroded $\mathrm{Cu}$ alloys, that chlorine is preferably deposited as an inner layer, in between the alloy's bulk and the outer corrosion layer. This preferential deposition is created by a mechanism originating from mechanical stress or chemical reaction, in which cracking occurs on the surface and promotes pitting corrosion. This process causes a further dissolution of the alloy, producing more $\mathrm{Cu}^{+}$cations that react with the $\mathrm{Cl}^{-}$anions present in the solution. As a result, $\mathrm{CuCl}$ and $\mathrm{CuCl}_{2}$ are formed and build up in a layer internal to the corrosion surface. Even though the formation of chloride compounds is propelled in this mechanism, the resulting weight percentage concentration of chlorine is still relatively low (when compared to the alloying element concentration and the system detection limit), commonly about 2 wt.\%. Moreover, if chloride compounds are to be deposited underneath a $\mathrm{Cu}$-oxide layer, the $\mathrm{Cl}$ detection by the MA-XRF system is further hindered by attenuation effects, thus making its detection extremely difficult.

Chlorine has a low atomic number $(Z=17)$ and, therefore, its fluorescence line energies are very low. Heavier atoms, such as copper, present in any given overlapping layer, can easily absorb chlorine's signal coming from underneath. 


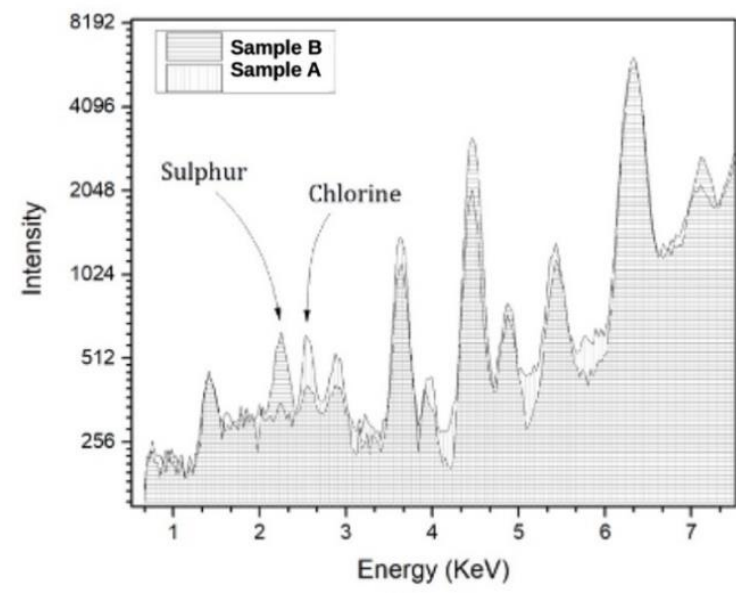

Figure 5. Sum spectra comparison of sample A and sample B. Arrows point to $\mathrm{S}-\mathrm{K} \alpha$ and $\mathrm{Cl}-\mathrm{K} \alpha$ lines.

\subsubsection{Reference sample $B$}

Figure 6 shows the total counts (sum) map alongside the elemental maps and a picture of the surface of sample $B$ after being immersed in the sulphate-containing solution.

As a first approach, sample roughness and scanner response must be interpreted, as they can play a significant role as major geometrical variables that may affect the scanner performance. Therefore, a comparison between roughness and the sum map can show the presence of a geometrical factor that creates a sort of distortion to the scanner response. If the counts per pixel and $\mathrm{Cu}$-peak signal-to-noise ratio are relatively high, it is possible to determine, through the total counts (sum) map, if there are any roughness contributions to the final images.

In fact, when applying an average-threshold filter (cutting off pixels with a centre-weighted average lower than the threshold input value) to the copper maps, a certain gradient in the intensity can be appreciated. Initially, the reasons can be three-fold: (a) the formation of a variable in the thickness corrosion product layer that attenuates (proportionally to its thickness) the signal from the copper atoms underneath; (b) a selective/preferential corrosion of copper; or (c) a distortion caused merely by the surface roughness.

After carefully inspecting the elemental maps of copper and sulphur from sample B, the sample's aspect (Figure 6) and the relatively smooth surface presented by the profiles obtained, it is reasonable to assume that what caused the gradient in the copper intensity is the presence of a thicker corrosion product layer area (whiteish region, Figure 6A) in the upper part of the sample surface. The corrosion product layer thickness can vary greatly, depending on the nature of the products present and the alloy. As an approximation, for bronzes, its thickness can vary from 40 to $138 \mu \mathrm{m}$ in the case of tin bronzes and from 14 to $146 \mu \mathrm{m}$ in the case of quaternary bronzes [30]. Therefore, even though a pure copper corrosion product layer thickness is not completely comparable to that of bronzes, it is still unlikely that, in this case, roughness would cause any significant distortion in the elemental distribution maps.

Concerning the corrosion compounds distributed across the sample surface, the chemical elements that can be associated with any corrosion product formed are copper, sulphur and chlorine (since oxygen cannot be detected by the instrument). In addition, $\mathrm{Cl}$ and $\mathrm{S}$ are light (low Z) elements and their count statistics are very low (Figure 5). The presence of chlorine (although detected

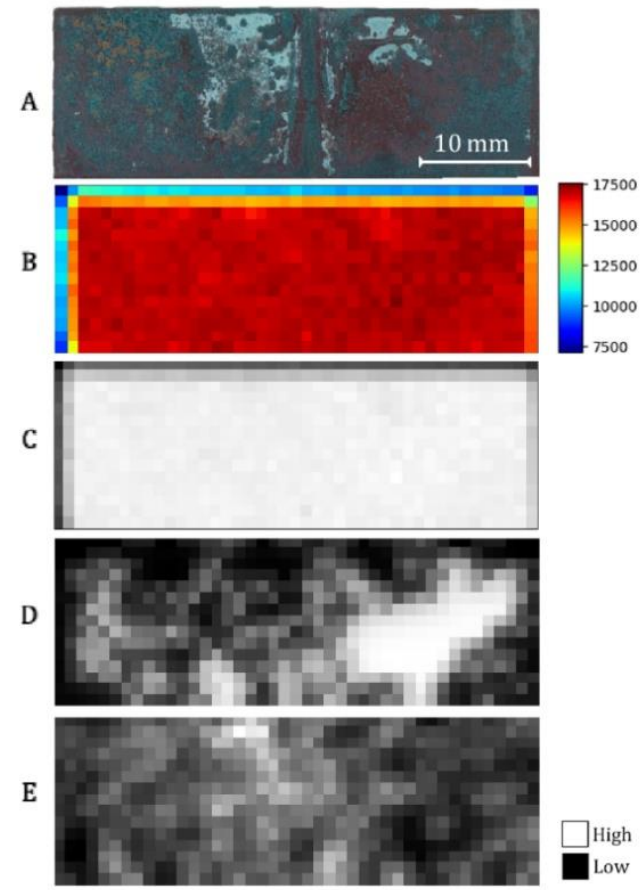

Figure 6. Sample B surface (A) and scans: (B) sum map; (C) copper map; (D) filtered copper map; (E) sulphur map.

by the instrument), probably belongs to the PVC sample holder instead of the copper surface itself (sample B), as observed in sample $A$. Sulphur was detected across the sample $B$ surface (as expected) and formed what seemed to be a gradient that spread from the upper-middle portion towards the lower region (Figure 3E). $\mu \mathrm{XRD}$ analyses on sample B suggest the presence of sulphur in the form of posnjakite and brochantite, so it is reasonable to assume the presence of sulphur.

\section{CONCLUSIONS}

This study allows a better understanding of the potential and capabilities of the prototyped MA-XRF scanner for the characterisation of $\mathrm{Cu}$-based artefacts. The scanner is able to identify the presence and surface distribution of the different elements, which is linked to the presence of different corrosion products on the metal surface.

Even though an in-depth corrosion assessment requires a multi-analytical approach to characterise the corrosion products from the microstructural and morphological perspective, MAXRF measurements can be successfully employed for a preliminary investigation, which can also be carried out in the field, highlighting the presence of stable and reactive corrosion products grown on the metal surface due to its interaction with the environment.

Future developments within the prototyped MA-XRF framework, apart from its application to different archaeological materials, will comprise its continuous assessment on real stratified corroded archaeological metals to increase its resolving capabilities and performance.

\section{ACKNOWLEDGEMENT}

The authors would like to thank the European Commission for financially supporting this research in the frame of the European Union's Horizon 2020 Research and Innovation Programme under the Marie Skłodowska-Curie grant agreement no. 766311. 


\section{REFERENCES}

[1] E. Angelini, F. Civita, S. Corbellini, D. Fulginiti, S. Grassini, M Parvis, Innovative monitoring campaign of the environmental conditions of the Stibbert museum in Florence, App. Phys. A, Materials Science \& Processing 122-123 (2016) pp. 1-12. DOI: $10.1007 / \mathrm{s} 00339-016-9635-4$

[2] S. Corbellini, E. Di Francia, S. Grassini, L. Iannucci L. Lombardo, M. Parvis, Cloud based sensor network for environmental monitoring, Measurement: Journal of the International Measurement Confederation 118 (2018) pp. 354-361.

DOI: $10.1016 /$ i.measurement.2017.09.049

[3] L. Lombardo, S. Corbellini, M. Parvis, A. Elsayed, E. Angelini, S. Grassini, Wireless sensor network for distributed environmental monitoring, IEEE Transactions on Instrumentation and Measurement 67 (2018) pp. 1214-1222.

DOI: $10.1109 /$ TIM.2017.2771979

[4] M. Samadelli, A.R. Zink, G. Roselli, S. Gabrielli, S. Tabandeh, V.C. Fernicola, Development of passive controlled atmosphere display cases for the conservation of cultural assets, J. Cult. Herit. 35 (2019) pp. 145-153.

DOI: $10.1016 /$ i.culher.2018.05.005

[5] E. Di Francia, R. Lahoz, D. Neff, E. Angelini, S. Grassini, Laser cleaning of $\mathrm{Cu}$-based artefacts: laser-corrosion products interaction, Acta IMEKO 7 (2018) 3, pp. 104-110.

DOI: $\underline{10.21014 / \mathrm{acta} \text { imeko.v7i3.610 }}$

[6] M. Matteini, C. Lalli, I. Tosini, A. Giusti, S. Siano, Laser and chemical cleaning tests for the conservation of the Porta del Paradiso by Lorenzo Ghiberti, J. Cult. Herit. 4 (2003) pp. 147-151. DOI: $10.1016 /$ S1296-2074(02)01190-1

[7] L. Robbiola, J.-M. Blengino, C. Fiaud, Morphology and mechanisms of formation of natural patinas on archaeological $\mathrm{Cu}-$ Sn alloys, Corrosion Science 40 (1998) pp. 2083-2111.

DOI: $10.1016 /$ S0010-938X(98)00096-1

[8] S. A. Barcellos Lins, E. Di Francia, S. Grassini, G. E. Gigante, S. Ridolfi, MA-XRF measurement for corrosion assessment on bronze artefacts, Proc. of IMEKO International Conference on Metrology for Archaeology and Cultural Heritage, Florence, Italy, 4-6 December 2019. Online [Accessed 13 March 2021] IMEKO-TC4-METROARCHAEO-2019-105.pdf

[9] L. Robbiola, C. Fiaud. Apport de l'analyse statistique des produits de corrosion à la compréhension des processus de dégradation des bronzes archéologiques, Revue d'Archéométrie 16 (1992) pp. 109 119. Online [Accessed 13 March 2021] www.persee.fr/doc/arsci 0399-1237 1992 num $16 \quad 1 \quad 896$

[10] C. Soffritti, E. Fabbri, M. Merlin, G. L. Garagnani, C. Monticelli, On the degradation factors of an archaeological bronze bowl belonging to a private collection, Applied Surface Science 313 (2014) pp. 762-770.

DOI: $10.1016 /$ j.apsusc. 2014.06 .067

[11] M.C. Bernard, S. Joiret. Understanding corrosion of ancient metals for the conservation of cultural heritage, Electrochimica Acta 54 (2009) pp. 5199-5205.

DOI: $10.1016 /$ i.electacta.2009.01.036

[12] E. Sidot, N. Souissi, L. Bousselmi, E. Triki, L. Robbiola, Study of the corrosion behaviour of $\mathrm{Cu}-10 \mathrm{Sn}$ bronze in aerated $\mathrm{Na}_{2} \mathrm{SO}_{4}$ aqueous solution, Corrosion Science 48 (2006) pp. 2241-2257. DOI: $10.1016 /$ j.corsci.2005.08.020

[13] D.A. Scott, Copper and Bronze in Art: Corrosion, Colorants, Conservation, 1st Edition, Getty publications, 2002, ISBN 9780892366385 .

[14] L. Selwyn, Metals and Corrosion: a Handbook for the Conservation Professional, 1st Edition, Canadian Conservation Institute, 2004, ISBN: 978-0662379843.

[15] L. Robbiola, R. Portier, A global approach to the authentication of ancient bronzes based on the characterization of the alloypatina-environment system, J. Cult. Herit. 7 (2006) pp. 1-12. DOI: $10.1016 /$ j.culher.2005.11.001

[16] M. Guerra, The study of the characterization and provenance of coins and other metalwork using XRF, PIXE and Activation
Analysis, in: Radiation in Art and Archeometry, D. C. Creagh, D. A. Bradley (editors) Elsevier: Amsterdam, The Netherlands, 2000, ISBN 978-0-444-50487-6, pp. 378-416.

DOI: $10.1016 /$ B978-044450487-6/50063-8

[17] S. Ridolfi, Gilded copper studied by non-destructive energydispersive X-ray fluorescence, Insight - Non-Destructive Testing and Condition Monitoring 60 (2018) pp. 37-41.

DOI: $\underline{10.1784 / \text { insi.2018.60.1.37 }}$

[18] S. Ridolfi, M. Laurenzi Tabasso, A. Askari Chaverdi, P. Callieri, The finishing technique of the stone monuments of Persepolis: further studies and new findings through the use of nondestructive analytical techniques, Archaeometry 61 (2019), pp. 271-281. DOI: $10.1111 / \operatorname{arcm} .12417$

[19] D. Howard, M. De Jonge, D Lau, D. Hay, M. Varcoe-Cocks, C. Ryan, R. Kirkham, G. Moorhead, D. Paterson, D. Thurrowgood, High-definition X-ray fluorescence elemental mapping of paintings, Analytical Chemistry 84 (2012), pp. 3278-3286. DOI: $10.1021 / \mathrm{ac} 203462 \mathrm{~h}$

[20] R. Cesareo, S. Ridolfi, A. Brunetti, R.T. Lopes, G.E. Gigante, First results on the use of a EDXRF scanner for 3D imaging of paintings, Acta IMEKO 7 (2018) 3, pp. 8-12. DOI: $10.21014 /$ acta imeko.v7i3.549

[21] A. Galli, M. Caccia, R. Alberti, L. Bonizzoni, N. Aresi, T. Frizzi, L. Bombelli, M. Gironda, M. Martini, Discovering the material palette of the artist: ap-XRF stratigraphic study of the Giotto panel 'God the Father with Angels', X-Ray Spectrometry 46 (2017), pp. 435-441.

DOI: $\underline{10.1002 / \mathrm{xrs} .2751}$

[22] B. Rosales, R. Vera, G. Moriena, Evaluation of the protective properties of natural and artificial patinas on copper. Part I. Patinas formed by immersion, Corrosion Science 41 (1999) pp. 625-651. DOI: $\underline{10.1016 / \text { S0010-938X(98)00108-5 }}$

[23] I. Constantinides, A. Adriaens, F. Adams, Surface characterization of artificial corrosion layers on copper alloy reference materials, Applied Surface Science 189 (2002), pp. 90-101.

DOI: $10.1016 /$ S0169-4332(02)00005-3

[24] M. Iorio, V. Graziani, S. Lins, S. Ridolfi, P. Branchini, A. Fabbri, G. Ingo, G. Di Carlo, L. Tortora, Exploring manufacturing process and degradation products of gilt and painted leather, Applied Sciences 9 (2019), pp. 3016.

DOI: $10.3390 /$ app9153016

[25] S.A. Barcellos Lins, S. Ridolfi, G.E. Gigante, R. Cesareo, M. Albini, C. Riccucci, G. Di Carlo, A. Fabbri, P. Branchini, L. Tortora, Differential X-ray attenuation in MA-XRF analysis for a non-invasive determination of gilding thickness, Frontiers in Chemistry 8 (2020), pp.1-9. DOI: $10.3389 /$ fchem.2020.00175

[26] S. A. Barcellos Lins, G. E. Gigante, R. Cesareo, S. Ridolfi, Recent developments on portable XRF scanner, Proc. of IMEKO International Conference on Metrology for Archaeology and Cultural Heritage, Florence, Italy, 4-6 December 2019, pp. 109113. Online [Accessed 13 March 2021] IMEKO-TC4-METROARCHAEO-2019-21.pdf

[27] S. A. Barcellos Lins, B. Bremmers, G. E. Gigante, XISMuS - Xray fluorescence imaging software for multiple samples, SoftwareX 12 (2020) pp. 100621.

DOI: $10.1016 /$ i.softx.2020.100621

[28] Malachite mineral data, Mineralogy Database. Online. [Accessed on 3 March 2020] http://webmineral.com/data/Malachite.shtml\#.Xpndp51S9PY

[29] Cuprite mineral data, Mineralogy Database. Online. [Accessed on 3 March 2020] http://webmineral.com/data/Cuprite.shtml\#.Xpm9e51S9PY

[30] H. W. Nørgaard, Portable XRF on prehistoric bronze artefacts: limitations and use for the detection of Bronze Age metal workshops, Open Archaeology 3 (2017) pp.101-122 DOI: $\underline{10.1515 / \text { opar-2017-0006 }}$ 